\title{
Metal oxide nanostructures synthesized on flexible and solid substrates and used for catalysts, UV detectors and chemical sensors
}

Magnus Willander, Azar Sadollah Khani, Ahmad Echresh and Omer Nour

\author{
Linköping University Post Print
}

Tweet

N.B.: When citing this work, cite the original article.

Original Publication:

Magnus Willander, Azar Sadollah Khani, Ahmad Echresh and Omer Nour, Metal oxide nanostructures synthesized on flexible and solid substrates and used for catalysts, UV detectors and chemical sensors, 2015, OXIDE-BASED MATERIALS AND DEVICES VI, 936414.

http://dx.doi.org/10.1117/12.2086803

Copyright: (C) 2015 SPIE

http://proceedings.spiedigitallibrary.org/

Postprint available at: Linköping University Electronic Press

http://urn.kb.se/resolve?urn=urn:nbn:se:liu:diva-119273 


\title{
Metal oxide nanostructures synthesized on flexible and solid substrates and used for catalysts, UV detectors and chemical sensors
}

\author{
Magnus Willander*a, Azar Sadollahkhani ${ }^{\mathrm{a}}$, Ahmad Echresh ${ }^{\mathrm{a}}$, Omer Nur ${ }^{\mathrm{a}}$ \\ ${ }^{a}$ Department of Science and Technology, Linköping University, SE-601 74 Norrköping, Sweden
}

\begin{abstract}
In this paper we demonstrate the visibility of the low temperature chemical synthesis for developing device quality material grown on flexible and solid substrates. Both colorimetric sensors and UV photodetectors will be presented. The colorimetric sensors developed on paper were demonstrated for heavy metal detection, in particular for detecting copper ions in aqueous solutions. The demonstrated colorimetric copper ion sensors developed here are based on $\mathrm{ZnO} @ \mathrm{ZnS}$ core-shell nanoparticles (CSNPs). These sensors demonstrated an excellent low detection limit of less than 1 ppm of copper ions. Further the colorimetric sensors operate efficiently in a wide pH range between 4 and 11 , and even in turbulent water. The CSNPs were additionally used as efficient photocatalytic degradation element and were found to be more efficient than pure $\mathrm{ZnO}$ nanoparticles (NPs). Also p-NiO/n- $\mathrm{ZnO}$ thin film/nanorods pn junctions were synthesized by a two-step synthesis process and were found to act as efficient UV photodetectors. Additionally we show the effect of the morphology of different $\mathrm{CuO}$ nanostructures on the efficiency of photo catalytic degradation of Congo red organic dye.
\end{abstract}

Keywords: Nanostructures, zinc oxide, nickel oxide, copper oxide, colorimetric sensors, photocatalytic degradation, UV photodetectors, photo catalytic degradation

\section{INTRODUCTION}

Zinc oxide $(\mathrm{ZnO})$ is an interesting semiconductor having a wide direct band gap (3.37eV) with many promising different applications such as photocatalysts, photodetectors, intrinsic white light emitting diodes, and for ultraviolet lasers etc.. [1]. More over $\mathrm{ZnO}$ can be synthesized using different physical and chemical methods. Recently the chemical methods have attracted the attention on researchers from many laboratories. Among the chemical methods, the hydrothermal methods are an attractive option. The interest to synthesize $\mathrm{ZnO}$ using chemical methods stems from the easiness of the method, it's low cost, and possibility of scale up. In addition, the precipitation method is among the most popular due to their simplicity and relatively good yield. Using the chemical approach different morphologies of ZnO can be synthesized.

To fully utilize the superior properties of $\mathrm{ZnO}$, pn junctions are essential, since it is still difficult to synthesize stable ptype $\mathrm{ZnO}$, the option of forming heterojunction is the possible path. With the nanostructures having small foot print, it is possible to synthesize device quality $\mathrm{ZnO}$ on other substrates. In addition, it is possible also to synthesize $\mathrm{ZnO}$ and then in a second step growing another material on top of it to form heterojunction form composite nanostructures. Since $\mathrm{ZnO}$ is n-type by unintentional growth, it will be of use to combine it with other p-type material, like e.g. nickel oxide (NiO). It is known that coating nanoparticles (NPs) with a different semiconductor can dramatically change the properties of the original core material. Zinc sulfide $(\mathrm{ZnS})$ with wide band gap (3.66 eV) [2] is one of the candidates as a coating material and has potential applications such as electroluminescent devices [3], sensors and lasers [4]. ZnO@ZnS core shell nanoparticles (CSNPs) possess improved physical and chemical properties that are of potential for different applications. Due to this, many researchers have devoted considerable effort to design and control the synthesis of ZnO@ZnS CSNPs. Different ZnO@ZnS core-shell nanostructures have been synthesized but most of them were grown using methods rely on elevated temperature [5-7]. It will be of interest to synthesize $\mathrm{ZnO} @ \mathrm{ZnS}$ at low temperature to enable the use of soft

*magnus.willander@liu.se 
and flexible substrates. There are some few attempts to synthesize $\mathrm{ZnO} @ \mathrm{ZnS}$ using the low temperature, low cost chemical approach, but so far only a limited number of publications using the low temperature synthesis can be found [8, 9].

In this work, we show a simple fast reliable method to grow ZnO@ZnS CSNPs with full coverage using a simple two steps low temperature chemical method. In this way the $\mathrm{ZnO}$ NPs are completely covered with $\mathrm{ZnS}$ without using any additional capping agent. The resulting $\mathrm{ZnO} @ \mathrm{ZnS}$ core-shell nanoparticles were implemented on paper and were then used for colorimetric sensing of copper ions in aqueous solutions and they were also used as efficient photocatalyst for degradation of toxic dyes. In addition to this, we present the growth of composite $\mathrm{p}-\mathrm{NiO} / \mathrm{n}-\mathrm{ZnO}$ thin film/nanorods using a simple two-step process. The grown $\mathrm{p}-\mathrm{NiO} / \mathrm{n}-\mathrm{ZnO}$ hetero composite was used as an efficient UV detector. Different complementary analytical tools were used to characterize the synthesized nanostructures. Further the effect of the nanostructure morphology of $\mathrm{CuO}$ nanostructures on the photocatalytic degradation of Congo red organic dye is investigated.

\section{EXPERIMENTAL}

All chemical used were of analytical grade and were purchased from Sigma Aldrich and were used without further purification. The $\mathrm{ZnO}$ NPs were prepared by using the co-precipitation method. First, zinc acetate dehydrates $\left(\mathrm{ZnAC}_{2} \cdot 2 \mathrm{H}_{2} \mathrm{O}\right)$ and sodium hydroxide $\mathrm{NaOH}$ was dissolved in deionized water to form two transparent solutions with $0.5 \mathrm{M}$ and $1 \mathrm{M}$ concentrations, respectively. Then using two pipettes, the two solutions were poured into a beaker at room temperature. The mixture was stirred for $2 \mathrm{hrs}$ and a white precipitate was formed in the solution. The precipitated NPs were separated by centrifugation. Finally, pure ZnO NPs were obtained by washing the precipitate by deionized water and acetone and were dried in an oven at $75{ }^{\circ} \mathrm{C}$. To form $\mathrm{ZnO} @ \mathrm{ZnS}$ CSNPs, the ZnO NPs were covered with the $\mathrm{ZnS}$ using a simple chemical method. A $0.3 \mathrm{~g}$ of the as-grown $\mathrm{ZnO}$ NPs with $50 \mathrm{ml}$ isopropanol was sonicated for 10 $\mathrm{min}$. Then this was followed by adjusting the $\mathrm{pH}$ to 10 using ammonium hydroxide, and then a solution of $\mathrm{Na}_{2} \mathrm{~S}$ was added to the mixture drop wise. This mixture was kept under continuous stirring at $60{ }^{\circ} \mathrm{C}$ for $2 \mathrm{hrs}$. Finally, in order to achieve the formation of $\mathrm{ZnO} @ \mathrm{ZnS}$ CSNPs with full coverage of the shell material, a solution of $0.05 \mathrm{M} \mathrm{ZnCl}_{2}$ was added drop wise to the above mixed solution and it was stirred for $1 \mathrm{hr}$. Finally, the produced CSNPs were washed with deionized water and acetone and was left in an oven to dry at $70{ }^{\circ} \mathrm{C}$. In order to investigate the effect of the shell thickness on the structural properties of the ZnO@ZnS CSNPs, the samples were synthesized with different concentrations of the $\mathrm{Na}_{2} \mathrm{~S}$ solution $(0.025 \mathrm{M}, 0.05 \mathrm{M}$, and $0.1 \mathrm{M})$. The collected CSNPs powder was later used and deposited on paper substrate and used as copper ions colorimetric sensor.

The $\mathrm{p}-\mathrm{NiO} / \mathrm{n}-\mathrm{ZnO}$ thin film/nanorods were grown using a two-step process, the details of this process are as follows: commercially available fluorine doped tin oxide (FTO) glass substrate was used in this study. The FTO glass substrate was cleaned by sonication in acetone, deionized water, and isopropanol, respectively. Part of the substrate at the edge was covered with scotch tape in order to be used as a metal contact area. Then the substrate was coated by a ZnO NPs seed layer as described in [10]. The coating with ZnO NPs was used to improve the quality and alignment of the grown $\mathrm{ZnO}$ nanorods. To grow the $\mathrm{ZnO}$ nanorods, an equimolar concentration of hexamethylenetetramine (HMT) and zinc nitrate hexahydrate solutions $(0.075 \mathrm{M})$ were separately prepared and mixed together. Then the final solution was poured into a beaker and the pretreated substrate was immersed in the solution with the growth side facing downward. The beaker was then sealed and was placed in a preheated laboratory oven at $95{ }^{\circ} \mathrm{C}$ for 5 hours. The beaker was allowed to cool down to room temperature. After the growth process, the sample was rinsed with deionized water to remove the residual salts and it was dried with nitrogen blow. To fabricate the $\mathrm{p}-\mathrm{NiO}$ thin film $/ \mathrm{n}-\mathrm{ZnO}$ nanorods heterojunction, $\mathrm{Ni}$ film with $50 \mathrm{~nm}$ thickness was deposited by thermal evaporation in a vacuum chamber with a pressure of $2 \times 10^{-6} \mathrm{mbar}$ on top of the $\mathrm{ZnO}$ nanorods. Oxidation was then used to transform the $\mathrm{Ni}$ to $\mathrm{NiO}$ thin film. Then to oxidize the Ni film, the sample was annealed in oxygen ambient at a temperature of $400{ }^{\circ} \mathrm{C}$ for 5 hours. To prepare the UV detector device, $\mathrm{Ag}$ circular contact with $80 \mathrm{~nm}$ thickness and $1 \mathrm{~mm}$ diameter was afterwards deposited on the top of the $\mathrm{NiO}$ thin film using thermal evaporation method. Since the morphology of nanostructures has a great influence on the properties and performance of the nanomaterial, different $\mathrm{CuO}$ nanostructures (nanorods, nanoleaves and nanosheets) were synthesized by the low temperature chemical growth and were used as photocatalytic degradation elements. The detailed of the synthesis can be found in [11].

The structural characterization of the grown CSNPs and the thin film/nanostructures composite were investigated by Xray powder diffraction (XRD) using a Phillips PW 1729 powder diffractometer equipped with $\mathrm{CuK} \alpha$ radiation $(\lambda=1.5418$ 
A) operating at a generator voltage of $40 \mathrm{kV}$ and a current of $40 \mathrm{~mA}$. A LEO 1550 Gemini field emission scanning electron microscope working at $15 \mathrm{kV}$ was used to investigate the morphology of the ZnO@ZnS CSNPs. An Equinox 55

\section{RESULTS AND DISCUSSION}

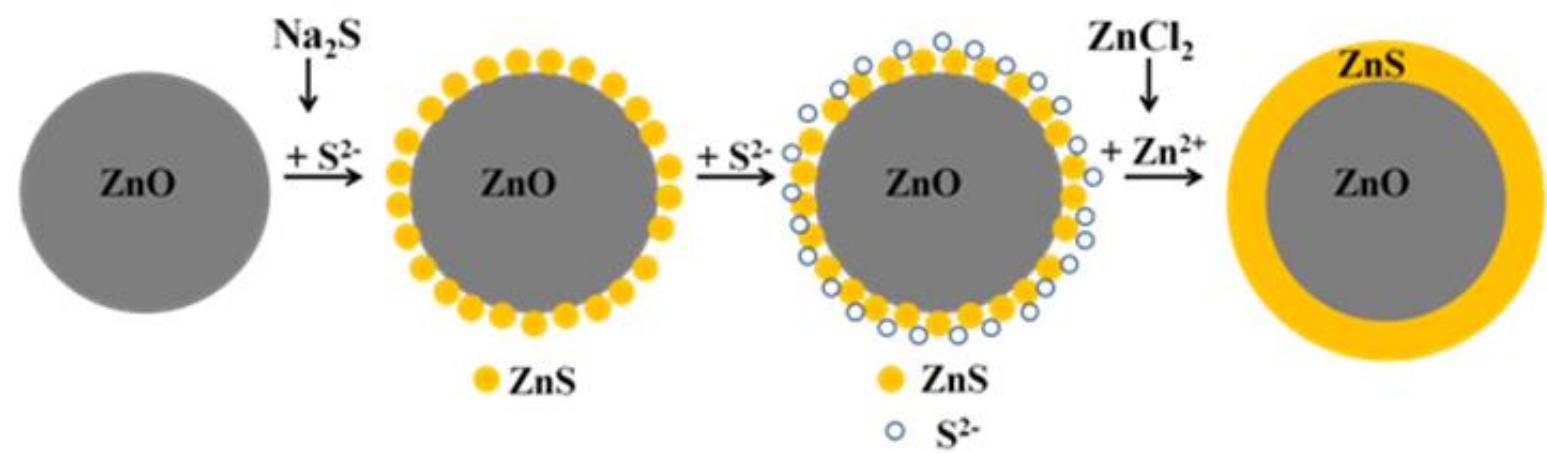

Figure 1. Schematics diagram showing the mechanism of the synthesizing the ZnO@ZnS CSNPs.

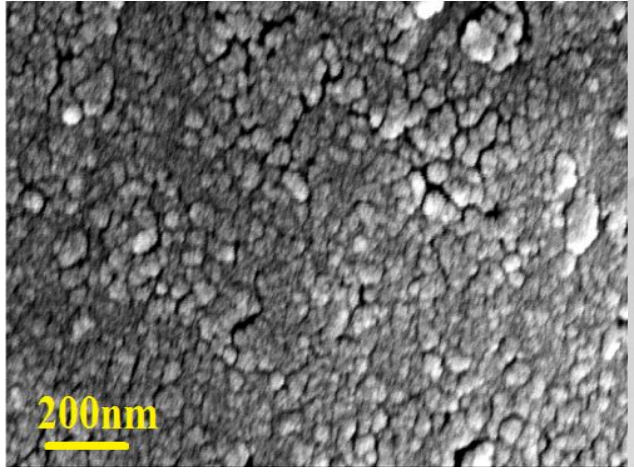

(a)

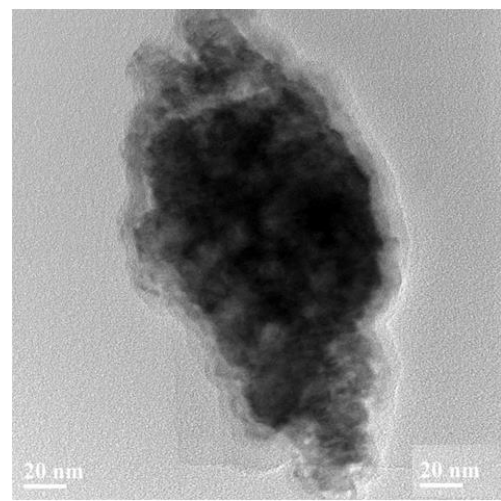

(c)

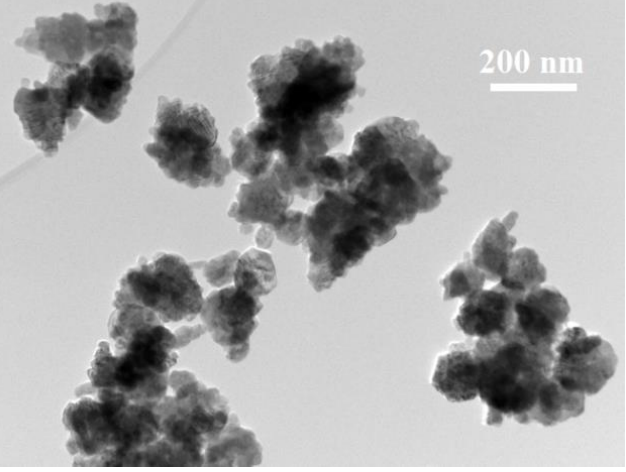

(b)

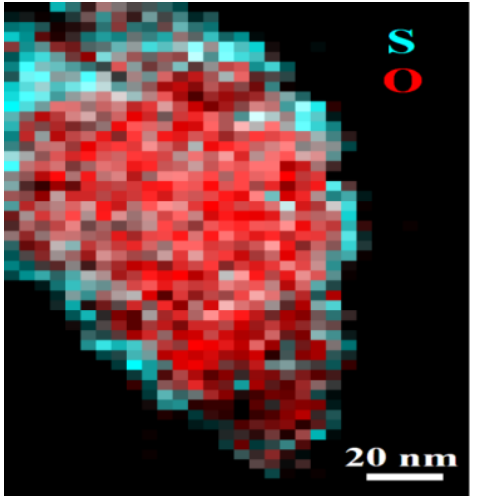

(d)

Figure 2. (a) Low resolution SEM image showing the ZnO@ZnS CSNPs, (b) Bright field TEM image of pure ZnO NPs, (c), and in (d) EDX mapping showing the S, O and $\mathrm{Zn}$ distribution.

FT-IR spectrometer was used in order to reach further information about the products and their surfaces. The HRTEM characterization was carried out by using a FEI Tecnai G2 TF20 UT instrument with a field-emission gun operated at 
$200 \mathrm{kV}$. The instrument has a point resolution of $0.19 \mathrm{~nm}$ and is equipped with an energy dispersive $\mathrm{x}$-ray spectroscopy (EDX) system. The TEM specimen was prepared by dispersing the nanostructure powder on a copper grid with a thin amorphous carbon film. The UV detection characteristics were evaluated by semiconductor parameter analyzer and Potentiostat (Autolab) under lamp illumination at $\lambda_{\max }=365 \mathrm{~nm}$ with a light power of $18 \mathrm{~W}$.

After dispersing the $\mathrm{ZnO}$ NPs in isopropanol, the $\mathrm{pH}$ of the solution was adjusted to around 10. Since the $\mathrm{ZnO}$ NPs are soluble in acidic and basic $\mathrm{pH}$ values, the surface of the $\mathrm{ZnO}$ NPs will start to be etched and the $\mathrm{S}^{2-}$ from the $\mathrm{Na}_{2} \mathrm{~S}$ which is added to the NPs solution will react with the $\mathrm{Zn}^{2+}$ and a thin layer $\mathrm{ZnS}$ is formed around the $\mathrm{ZnO}$ NPs:

$$
\mathrm{Zn}^{2+}+\mathrm{S}^{2-} \rightarrow \mathrm{ZnS}
$$

The thin layer of the $\mathrm{ZnS}$ will isolate the $\mathrm{ZnO}$ NPs from the sulfur ions in the solution so that no more could be formed. By adding the $\mathrm{ZnCl}_{2}$ to the mixture as drop wise, the unreacted $\mathrm{S}^{2-}$ ions in the solution will react with the $\mathrm{Zn}^{2+}$ and will leads to form more ZnS around the surface of the NPs. The formation mechanism of ZnO@ZnS CSNPs is shown in the schematic diagram of figure 1. While in figure 2a a SEM of the final produced CSNPs is shown. While a bright field TEM image of the pure ZnO NPs is shown. The structural integrity of the CSNPs was further investigated by TEM. Figure 2c shows a bright field TEM image of a single ZnO@ZnS CSNP. To investigate the coverage of the shell on the core, EDX was used. Figure 2c shows EDX mapping exhibiting S, O and Zn distribution. It is clear that the $\mathrm{ZnS}$ shell has fully covered the $\mathrm{ZnO}$ core.

Figure 3 below shows the UV-visible spectra of ZnO NPs and the ZnO@ZnS CSNPs. As it is clear from the spectra, the absorption wavelength peak of the ZnO NPs is around $360 \mathrm{~nm}$ and it shifts to higher wavelength (372 nm) for ZnO@ZnS CSNPs. From the plot of the of $(\alpha h v)^{2}$ versus hv (not shown here), the bandgaps of the ZnO NPs and the $\mathrm{ZnO@ZnS} \mathrm{CSNPs} \mathrm{were} \mathrm{extracted} \mathrm{to} \mathrm{be} 3.08 \mathrm{eV}$ and, respectively. As can be noted the bandgap of the ZnO NPs is smaller than that of the bulk $\mathrm{ZnO}$ material. While the optical band gap of the $\mathrm{ZnO} @ \mathrm{ZnS}$ CSNPs was found to be $2.9 \mathrm{eV}$. This is smaller than that of the pure $\mathrm{ZnO}$ NPs as expected.

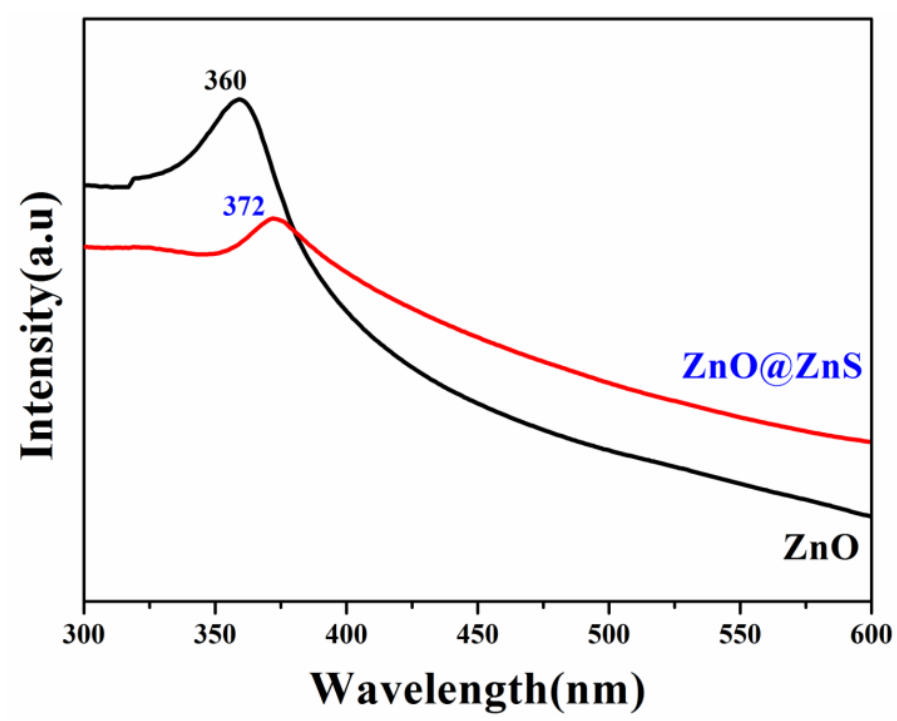

Figure 3. UV visible absorption spectra of ZnO NPs and ZnO@ZnO CSNPs. 


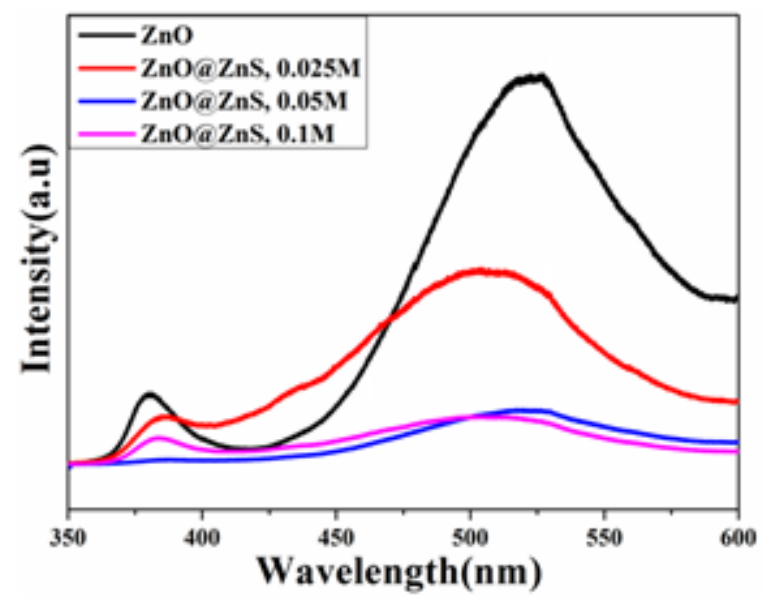

Figure 4. PL spectra of the ZnO NPs and the three ZnO@ZnS CSNPs samples.

Optical properties were further investigated using photoluminescence (PL) spectroscopy. We prepared three different CSNPs with different molar concentration of the sulfur ions source $(0.026 \mathrm{M}, 0.05 \mathrm{M}$, and $0.10 \mathrm{M})$. The Pl spectra of the samples are shown in figure 4. It was observed that the PL spectra for all samples were red-shifted with increasing the excitation power $\mathrm{P}_{\mathrm{exc}}$. It should be noticed that the observed peaks initially were growing in intensity with increasing the $\mathrm{P}_{\mathrm{exc}}$, and after a certain threshold, the red-shift starts to appear. We have obtained the PL spectra at a constant $\mathrm{P}_{\mathrm{exc}}$ for both the ZnO NPs and the ZnO@ZnS CSNPs samples. Hence the peak intensities can be compared. Also, the ratio of the near band edge (NBE) to the deep level emission (DLE) emission intensities can be used for comparison. The pure $\mathrm{ZnO}$ NPs demonstrates a narrow peak of ultraviolet (UV) emission at $378 \mathrm{~nm}$. The UV emission peak is due to free excitonic recombination. The next peak is centered at $513 \mathrm{~nm}$ and is much broader. This is so called "green-yellow" band of the visible luminescence or deep level emission (DLE) which is due to the deep levels formed by oxygen and zinc vacancies in the lattice. The ZnO@ZnS CSNPs demonstrate the same qualitative character of luminescence, i.e. having two peaks. Nevertheless for the CSNPs the peak position is different from that of the ZnO NPs for both the UV and DLE peaks. As it can clearly be seen, there is a slight red-shift for all the ZnO@ZnS CSNPs and this behavior could be expected from type II system. But by enhancing the sulfur source and consequently increase the shell thickness, the red-shift stars to be reduced. This could be due to the difference between the sizes of the samples.

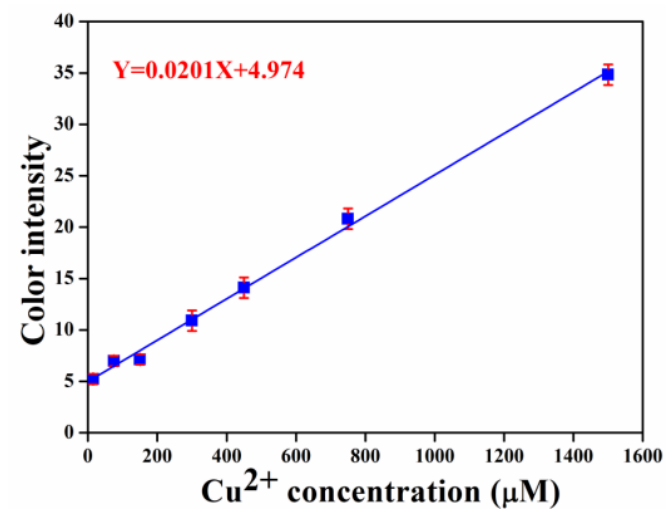

(a)

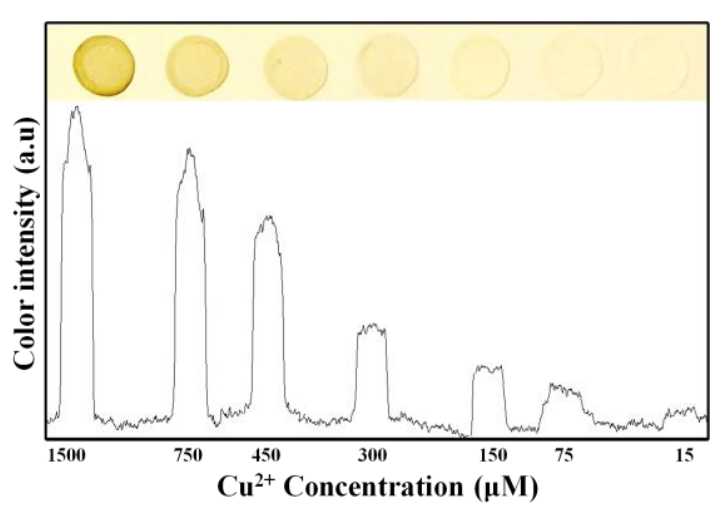

(b)

Figure 5. (a) Calibration curve colour intensity versus $\mathrm{Cu}^{2+}$ concentration, and (b) color intensity versus $\mathrm{Cu}^{2+}$ ionic concentration in aqueous solution. The insert shows a photograph of the sensor paper tested at different $\mathrm{Cu}$ ion concentrations. 
The ZnO@ZnS CSNPs synthesized as discussed above were deposited on paper and used as copper ion colorimetric sensor. The detection mechanism presented here relies on the cation exchange due to the large different of the solubility product constant between the $\mathrm{ZnS}$ and $\mathrm{CuS}$. Figure 5a above shows the calibration curve of the colorimetric $\mathrm{Cu}$ ions sensor. While in figure $5 \mathrm{~b}$ shows the color intensity versus $\mathrm{Cu}$ ions concentration. The lower detection limit of this colorimetric sensor was less than $1 \mathrm{ppm}$. Indeed this is an excellent sensitivity and much higher than the maximum allowed limit of the $\mathrm{Cu}$ ions in drinking water. It is also important that the present colorimetric sensor was tested in turbulent water and was found to operate efficiently. Further interference experiments were carried out (not shown here) and the results indicate that the sensor is not affected by the present of many other heavy metal ions. This implies that the present colorimetric sensor possesses acceptable selectivity. For more information about this sensor can be found in [12].
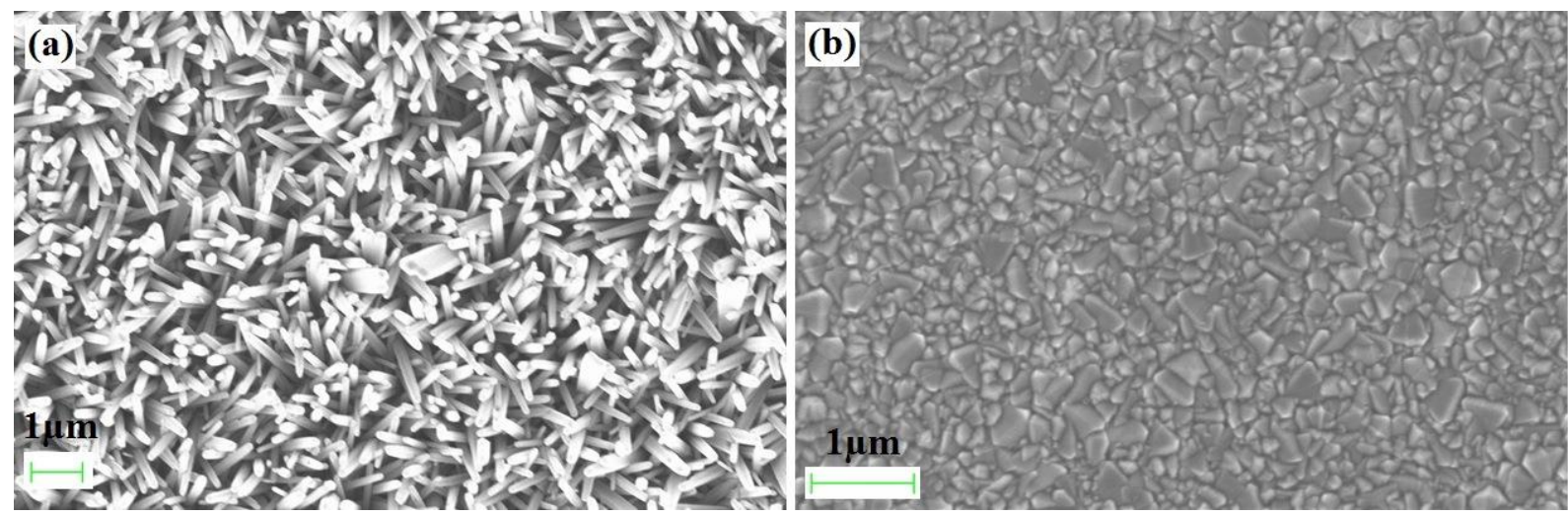

Figure 6.(a) SEM imageZnO nanorods grown on at low tempartue using the chemcial approach, and in (b) SEM of the n-Zno nanorods after the over gorwth of p-type $\mathrm{NiO}$ as described above.

Figure 6a shows the $\mathrm{n}-\mathrm{ZnO}$ nanorods synthesized as described above and were later used to form UVdetectors after the over gowth of $\mathrm{p}-\mathrm{NiO}$. The SEM in figure $6 \mathrm{~b}$ shows the $\mathrm{ZnO}$ nanorods after covering with the $\mathrm{p}-\mathrm{NiO}$ using a second growth step. It can be seen that relatively well aligned $\mathrm{ZnO}$ nanorods having hexagonal faces with average diameter and height of approximately $100 \mathrm{~nm}$ and $1 \mu \mathrm{m}$, respectively, have been achieved. Moreover, the NiO thin film is clearly seen to cover all the $\mathrm{ZnO}$ nanorods with relatively smooth surface.
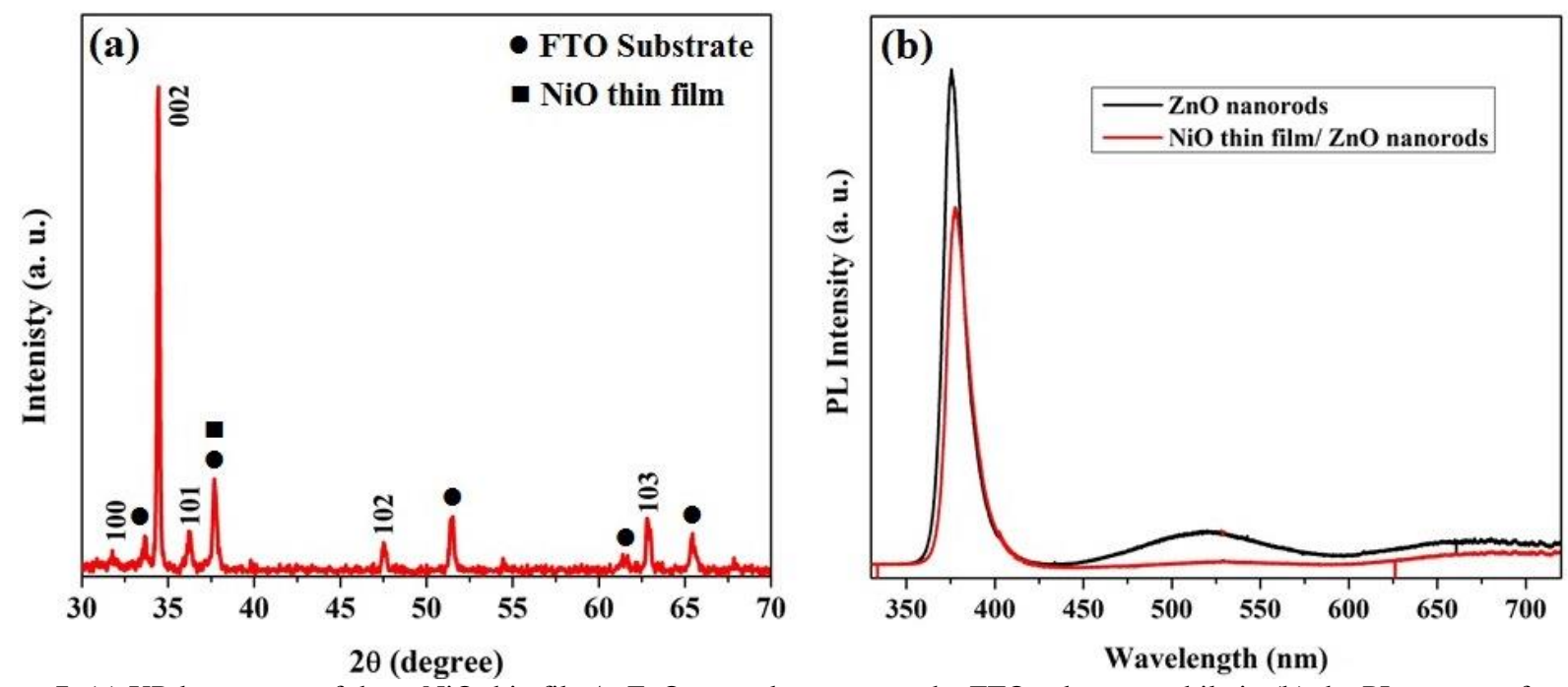

Figure 7. (a) XRd spectrum of the $\mathrm{p}-\mathrm{NiO}$ thin film/n-ZnO nanords gorwn on the FTO substrate, while in (b) the PL spectra of pure $\mathrm{n}$ $\mathrm{ZnO}$ nanorods and the $\mathrm{p}-\mathrm{NiO}$ thin film/n- $\mathrm{ZnO}$ nanorods are shown, respectively. 

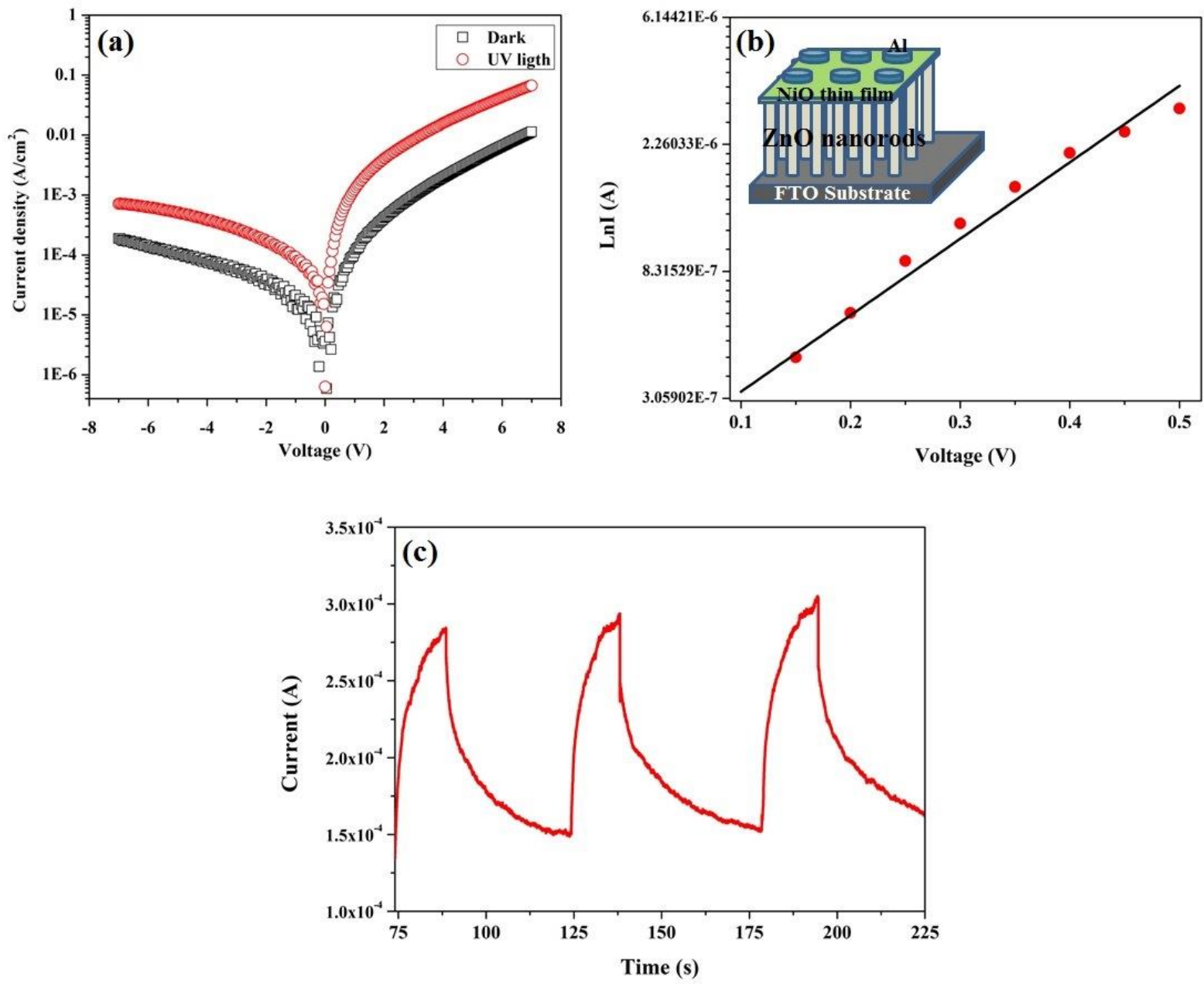

Figure 8. (a) Current density-voltage characteristics of the $\mathrm{p}-\mathrm{NiO}$ thin film/n-ZnO nanorods heterojunction, (b) the plot of ln (I) versus $\mathrm{V}$ used for the extraction of the ideality factor, the insert of the schematic diagram of the device, and (c) the diode photo response of the $\mathrm{p}-\mathrm{NiO} / \mathrm{n}-\mathrm{ZnO}$ heterojunction.

The crystal structure of the materials forming the heterojunction is investigated using XRD analysis by acquiring $\theta-2 \theta$ spectra. Figure 7a shows the XRD patterns of the $\mathrm{p}-\mathrm{NiO}$ thin film/ZnO nanorods/FTO heterojunction. It can be seen that the XRD pattern displays diffraction peaks that correspond to $\mathrm{ZnO}$ wurtzite structure (JCPDS No. 36-1451) with preferential orientation along the c-axis (002). The lattice constants extracted from the XRD data were $a=3.25 \AA$ and $\mathrm{c}=5.20 \AA$. In addition to this the XRD pattern show characteristic peaks of $\mathrm{NiO}$ which correspond to the (111) and (200) planes of the cubic NiO consistent with the (JCPDS No. 01-1239). The extracted lattice constant was calculated to be $\mathrm{a}=4.16 \AA$. It should be mentioned that the (111) direction of $\mathrm{NiO}$ thin film has the same angle with one of the peaks of the FTO glass substrate $\left(2 \theta=37.66^{\circ}\right)$.

The $\mathrm{n}-\mathrm{ZnO}$ nanorods and the $\mathrm{p}-\mathrm{NiO}$ thin film/n- $\mathrm{ZnO}$ nanorods were investigated by photoluminescence. All the spectra were taken with the same excitation power and integration time and are therefore comparable. It can be seen that the ultraviolet (UV) emission which is called near band edge emission (NBE) and two deep level emission (DLE) peaks are observed for $\mathrm{ZnO}$ nanorods approximately at $375 \mathrm{~nm}, 520 \mathrm{~nm}$ (DLE1, green emission) and $680 \mathrm{~nm}$ (DLE2, red emission), respectively. The UV emission is attributed to the recombination of free excitons and the green and red peaks are ascribed to the recombination between the conduction band and zinc interstitial $\left(\mathrm{Zn}_{\mathrm{i}}\right)$ energy level to oxygen vacancy 


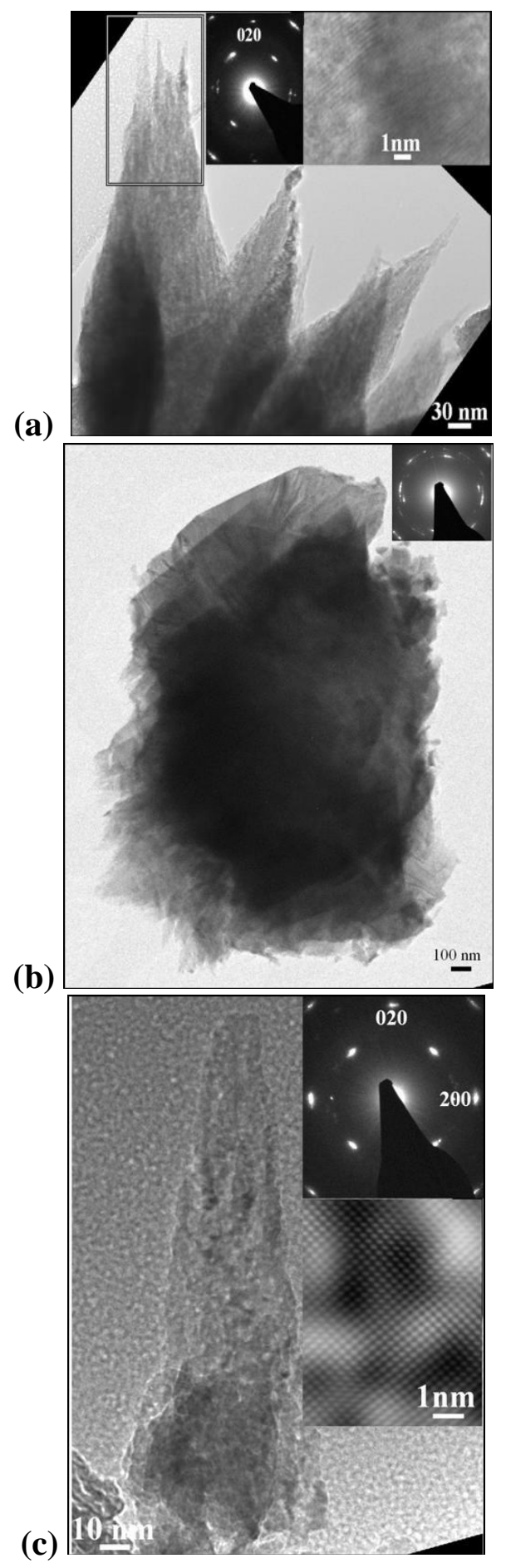

Figure 9.Transmission electron microscope images pf different $\mathrm{CuO}$ nanostructures, in (a) nanorods, (b) nanoleaves, and in (c) nanosheets. The inserts are selected area diffraction pattern indicating single crystal features.

$\left(\mathrm{V}_{\mathrm{O}}\right)$ and oxygen interstitial $\left(\mathrm{O}_{\mathrm{i}}\right)$, respectively. The $\mathrm{PL}$ emission intensity of the $\mathrm{NiO}$ thin film/ZnO nanorods heterojunction sample is lower than those of pure $\mathrm{ZnO}$ nanorods. This can be explained by possible absorption of the PL signal by the top NiO layer. This effect was particularly prominent for the defect luminescence. 
Figure 8 (a) displays the current density - voltage (J-V) characteristics of the p-NiO thin film/n-ZnO nanorods heterojunction in the dark and under UV illumination at room temperature. It is clearly that be seen the diode indicates an obvious rectifying behavior under both dark and UV illuminated. The turn-on voltage of the diode exhibits a low value indicating that the diode has fairly low power consumption. The value of the $\mathrm{I}_{\mathrm{F}} / \mathrm{I}_{\mathrm{R}}(=60$ in dark and $=90$ under UV illumination) ratio in the dark condition indicates high quality heterojunction where $I_{F}$ and $I_{R}$ is the current under forward bias and leakage current under reverse bias $(7 \mathrm{~V})$, respectively. To evaluate the ideality factor of the diode, the dark current - voltage (I-V) response of the diode at low bias can be modeled using the ideal diode equation. The ideality factor (n) and the reverse bias saturation current $\left(\mathrm{I}_{\mathrm{sat}}\right)$ can be calculated from the slope and intercept of the straight line of the forward bias from the $\ln (\mathrm{I})-\mathrm{V}$ plot, as shown in the figure 8 (b). The ideality factor of the diode $(\mathrm{n}=7)$ is much larger than that of an ideal diode $(n=1)$. This high value of $n$ suggests that the transport mechanism is not dominated by the thermionic emission, but consists of other mechanisms like e.g. defect assisted tunnelling with conventional electronhole recombination. A Potentiostat was used to check the decay time response of the diode. UV illumination was applied for $13 \mathrm{~s}$ and the gap between the UV illuminations to bring the diode to its stable position was about $40 \mathrm{~s}$ as shown in figure $8(\mathrm{c})$.

Since the morphology of a nanostructure can have a strong influence on the properties, different nano-morphologies of $\mathrm{CuO}$ were synthesized and their corresponding catalytic activity is investigated for degrading Congo red organic dye. Figure 9 shows different TEM images of the three investigated $\mathrm{CuO}$ morphologies.

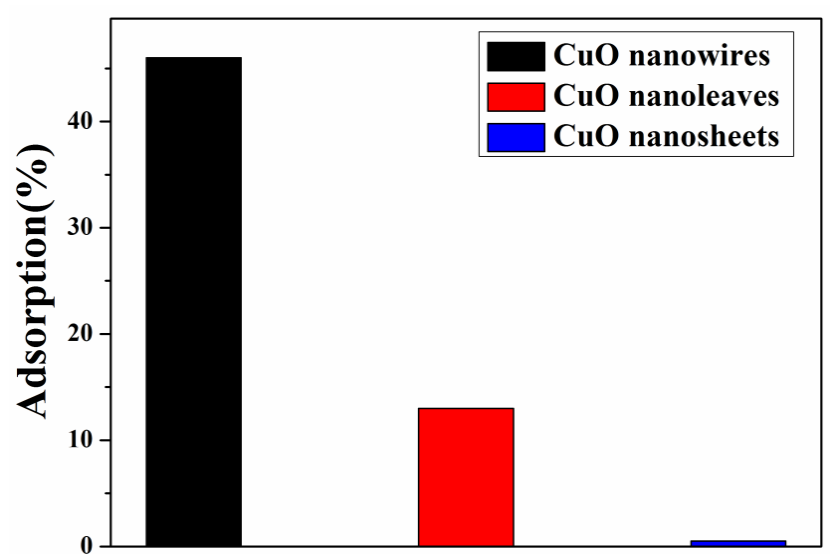

(a)

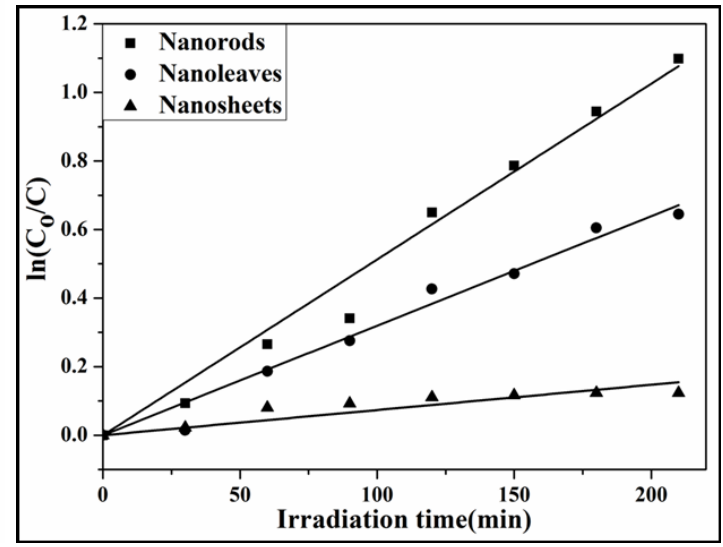

(b)

Figure 10. Adsorption of Congo red on the surface of different morphologies of $\mathrm{CuO}$, and in (b) The plot of $\ln (\mathrm{C} 0 / \mathrm{C})$ versus time for different $\mathrm{CuO}$ morphologies is shown.

Figure 9a shows a TEM image of the nanorods and a selected area electron diffraction pattern (SAED). It is clearly seen that the growth direction of the nanorods to be along the [010] direction. The SAED investigation has indicated that the monocrystalline phase of $\mathrm{CuO}$ which agrees fully with the XRD results (not shown here). The TEM analysis has clearly shown that the $\mathrm{CuO}$ nanostructures exhibit nanorods morphology. While figure $9 \mathrm{~b}$ shows a TEM image of the $\mathrm{CuO}$ nanosheets. The upper right inset is SAED of the same morphology. This SAED pattern revealed that the $\mathrm{CuO}$ nanosheets exhibit a monoclinic crystalline structure and the [010] and [100] are the growth directions. In figure 9c a TEM image of the nanoleaves is displayed. The corresponding TEM analysis image of the $\mathrm{CuO}$ nanoleaves is shown in figure 9c. This TEM image indicates that the $\mathrm{CuO}$ nanoleaves grow with a pattern perpendicular to the substrate. The SAED pattern was performed for a single nano leaf and is shown in the inset of figure $9 \mathrm{c}$ and the observed diffraction points demonstrate monoclinic structure of $\mathrm{CuO}$ and it also indicate that the $\mathrm{CuO}$ nanoleaves are single crystalline.

Photo-generated electron-hole pairs are responsible for degradation of dye pollutant in photocatalytic degradation process. The photo-generated $\mathrm{h}^{+}$in the valence band reacts with either $\mathrm{H}_{2} \mathrm{O}$ or $\mathrm{OH}^{-}$to produce the $\mathrm{HO}^{*}$. While the electrons in the conduction band reacts with adsorbed $\mathrm{O}_{2}$ on the surface of particle to generate $\mathrm{O}_{2}{ }^{\circ}$. The kinetics of the degradation of Congo red using all the different $\mathrm{CuO}$ morphologies were investigated and it was found that the degradation reactions of all three morphologies with Congo red showed pseudo first order kinetics for specific time of degradation. All the observed photo-degradation kinetics information was consistent with the linear equation: 


$$
\ln \left(\mathrm{C} / \mathrm{C}_{\mathrm{o}}\right)=-\mathrm{kt}
$$

where $\mathrm{C}_{\mathrm{o}}$ is the initial concentration of the dye and $\mathrm{C}$ is the concentration of the dye after a time $\mathrm{t}$ and $\mathrm{k}$ is a specific rate constant for the first order kinetics reaction.

Figure 10a shows the adsorption Congo red dye on the surface of the different $\mathrm{CuO}$ nanostructures. In view of the fact that decomposition of some dyes takes place on the surface of the photocatalyst, the adsorption of a dye is a crucial step in the photocatalytic degradation process. The maximum adsorption of the dye which was observed to be around $46 \%$ and it takes place when the $\mathrm{CuO}$ nanorods were used. The first order kinetics graph between the values of $\ln \left(\mathrm{C} / \mathrm{C}_{0}\right)$ vs time for the degradation of Congo red for the three different $\mathrm{CuO}$ morphologies is shown in figure 10b. Figure $10 \mathrm{~b}$ illustrates a linear correlation and it indicates that the Congo red degradation reaction follows first order kinetics for all the three $\mathrm{CuO}$ morphologies investigated (nanorods, nanosheets and nano leaves).

\section{CONCLUSION}

In conclusion we have used the low temperature chemical synthesis to obtain different metal oxide nanostructures. Different complementary structural characterization results demonstrate that relatively high crystal quality of different metal oxide nanostructures and core-shell nanoparticles has been achieved. The demonstrated nanomaterials include, $\mathrm{ZnO}, \mathrm{NiO}$, and $\mathrm{CuO}$. While the core-shell nanoparticles constituted $\mathrm{ZnO} @ \mathrm{ZnS}$ core-shell nanoparticles. The synthesized nanomaterial was used to develop copper ions colorimetric paper based sensors, UV photodetectors and photo-catalytic degradation material. Characterization of the devices indicated an acceptable performance. In general and in view of the fact that the used processes are scalable, the presented results indicate that the low temperature chemical synthesis process can be of potential to develop future low cost electronic devices on solid or soft substrates.

\section{REFERENCES}

[1] Willander, M., ul Hasan, K., Nur, O., Zainelabdin, A., Zaman, S, Amin, G., "Recent progress on growth and device development of $\mathrm{ZnO}, \mathrm{CuO}$ and graphene nanosheets", J. Mater. Chem, 22, 2337-2350 (2012).

[2] Onwudiwe, D. C., Strydom, C. A., "Colloidal-route synthesis of N-butylaniline capped ZnS and CdS nanoparticles", Mater Lett. 92, 71-74 (2013).

[3] Sahare, S., Dhoble, S. J., Singh, P., Ramrakhiani, M., "Fabrication of ZnS:Cu/PVA nanocomposite electroluminescence devices for flat panel displays", Adv. Mat. Lett. 4, 169-173 (2013).

[4] Fang, X., Bando, Y., Liao, M., Gautam, U. K., Zhi, C., Dierre, B., "Single-crystalline ZnS nanobelts as ultravioletlight sensors", Adv. Mater. 21, 2034-2039 (2009).

[5] Nam, W.H, Lim, Y. S., Seo, W. S., Lee, J. Y., "Sintering behavior and microstructures of nanostructured ZnO-ZnS core-shell powder by spark plasma sintering", Philosophical Magazine 93, 4221-4231 (2013).

[6] Zhang, X. T., Chen, M. L., Wen, J., Wu, L. L., Gao H., and D. Zhang, "Side by side ZnO/ZnS hetero-junction nanocrystal arrays with superior field emission property", Cryst. Eng. Comm. 15, 1908-1913 (2013).

[7] Fan, J. D., Fábrega, C., Zamani, R., Shavel, A., Güell, F., Carrete, A., Andreu, T., López, A. M., Morante, J. R., J. Arbiol, A. Cabot, " Solution-growth and optoelectronic properties of $\mathrm{ZnO}: \mathrm{Cl} @ \mathrm{ZnS}$ core-shell nanowires with tunable shell thickness", J. of Alloys and Compounds, 555, 213-218 (2013).

[8] Nam, W. H., Lim, Y. S., Seo, W. S., Cho, H. K., Lee, J. Y., J., "Control of the shell structure of ZnO-ZnS core-shell structure", Nanopart. Res. 13, 5825-5831 (2011).

[9] Sharma, S., Chawla, S., "Enhanced UV emission in $\mathrm{ZnO} / \mathrm{ZnS}$ core shell nanoparticles prepared by epitaxial growth in solution", Electron Mater Lett. 9, 267-271 (2013).

[10] Greene, L. E., Law M., Tan D. H., Montano M., Goldberger J., Somorjai G. and Yang, P., "General route to vertical $\mathrm{ZnO}$ nanowire arrays using textured $\mathrm{ZnO}$ seeds", J. Nano Letters 5, 1231 (2005).

[11] Sadollahkhani, A., Ibupoto, Z. H., Elhag, S., Nur, O., Willander, M., "Photocatalytic properties of different morphologies of $\mathrm{CuO}$ for the degradation of Congo redorganic dye", Ceraminc International 40, 11311-11317, (2014).

[12] Sadollahkhani, A., Hatamie, A., Nur, O., Willander, M., Zagar, B., Kazeminezhad, I., "Colorimetric disposable paper coated with $\mathrm{ZnO} @ \mathrm{ZnS}$ core-shell nanoparticles for detection of copper ions in aqueous solutions", Appl. Mater. Interfaces 6, 17694-17701 (2014). 